\title{
Early Initiation of Breastfeeding and Its Associated Factors Among Mothers Who Delivered Vaginally in South Gondar Zone Hospitals, Northwest
} Ethiopia, 2020

\section{Bekalu Getnet Kassa (iD) \\ Department of Midwifery, College of Health Science, Debre Tabor University, Debre Tabor, Amhara, Ethiopia}

Correspondence: Bekalu Getnet Kassa Email bekalugetnet947@gmail.com
This article was published in the following Dove Press journal:

This article was published in the following
International Journal of Women's Health

Purpose: The early onset of skin-to-skin itact es arages th iffant to breastfeed within one hour of birth. The aim of this was to as ws walence of early onset breastfeeding and its associated fa ors an vaginal dudivered mothers in hospitals in the South Gondar Zone of Northwest Ethiopia 2020.

Methods: From January 1 to February 03, 20.0, an institutional-based cross-sectional study was used in South G dar Zone ho itals. A total of 356 mothers delivered by vaginal were included. Data was co cted using a uestionnaire administered by the interviewer and entered into version 3.1 of $\mathrm{E}_{\mathrm{R}}$ ata, an hen exported to SPSS version 23.0.0. To classify factors correlate Wru outcome variables, logistic regression statistical analyses were used.

Result he stud ea, the prevalence of early breastfeeding initiation among vaginally del cred $\mathrm{my}$ hers wa $88.2 \%$. Mothers who had unintended pregnancy [adjusted $\mathrm{OR}=6.00$, $\mathrm{CI}=2$ [ 2 hal professional guidance [adjusted $\mathrm{OR}=2.75,95 \% \mathrm{CI}=1.2,5.6$ ] and expo with breastfeeding [adjusted $\mathrm{OR}=1.7995 \% \mathrm{CI}=1.19,2.68$ ] among vaginal delivered mo rs were positively correlated with early breastfeeding initiation.

Conclusio. The type of pregnancy and professional guidance among vaginally delivered thers were significantly associated with early initiation of breastfeeding. Communitybas - education and counseling on breastfeeding for pregnant mothers and encouraging all mothers to start early breastfeeding.

Keywords: proportion, early initiation of breastfeeding, Ethiopia

\section{Background}

Breastfeeding (BF) is the act of feeding the mother's milk to the infant. It is the preferred food to any product provided to the baby for all children, and it is cost effective, new, and easily accessible. ${ }^{1}$

In order to minimize baby, child and maternal morbidity and mortality, breastfeeding is both a primary public health policy and helps to manage a health-care costs. In addition to health benefits for the mother and economic benefits for the family and the society as a whole, it also offers the child nutritional, immunological, developmental and psychological benefits. ${ }^{2,3}$

Early breastfeeding initiation (EIBF) is described as bringing the newborn to the breast within one hour of birth. It is one of the ten effective steps of breastfeeding 
practice and one of the main measures of determining the effective practice of feeding infants and young children. ${ }^{4}$

The EIBF is important for stimulating the production of breast milk by mothers, increasing maternal-infant bonding, improving cognitive development, promoting optimal growth and metabolic skills, improving infant responses to infection and reducing allergic diseases, etc. $^{5,6}$

Globally, in the first month of life, 2.5 million children died in 2017, most of which occurred in the first week, of around 1 million dying on the first day and about 1 million dying in the next six days. In sub-Saharan Africa and South Asia, neonatal mortality was also highest, with an estimated 27 deaths per 1000 live births each in $2017 .^{7}$

In developing countries alone, the EIBF could save as many as 1.45 million lives each year by reducing deaths mainly due to childhood diarrheal disorders and lower respiratory tract infections, but children are still death in the area because of diarrheal disorders and lower respiratory tract infections due to delayed initiation of breastfeeding. ${ }^{8,9}$

Children in Ethiopia suffer from poor health; before their 5th birthday, approximately 472,000 children are dying every year, making Ethiopia 6th among the worl countries in terms of absolute number of child deaths. the first 30 days of life, the age distribution of de ${ }^{1}$ under Five was 55 per thousand live births, $29 \%$ om th first month to the 11th month of life, and 2\% fr the first year to the fourth decade. In Etb pia, o atal mortality is very high, making Ethior jixth in tho orld in neonatal mortality, and childrer, nt Eth via suffer ând die in large numbers from pre ntable and table factors, particularly delayed init an of hreastfeeding. ${ }^{10}$

Some factors influc the $\mathrm{ABF}$, including such sociodemographic, ob-ric acteris of mothers and health care sy port $\mathrm{s}$ vices o re. ${ }^{11,12}$

The E spian of Health also targeted an increase in tho portion of newborn babies put to breast within the first ho of life to $92 \%$ by 2015 as one strategy to improve infant hualth by recognizing the undeniable role of the EIBF in reducing child mortality. ${ }^{13}$

Fortunately, the 2016 Ethiopian Demographic and Health Survey (EDHS) showed that $73 \%$ of children who were breast-fed in the first hour of life and the Amhara region was the second lowest region in the EIBF, which was $66 \%{ }^{14}$

While evidence exists on the proportion and associated factors of EIBF in different regions of the world, so far there has been an information gap on the proportion and associated factors of early onset of breastfeeding among vaginal mothers who have been delivered. The goal of this study was indeed to determine the proportion of EIBF among vaginal delivered mothers and to identify factors affecting the EIBF in the South Gondar Zone, Northwest Ethiopia, 2020.

\section{Methods \\ Study Setting}

The study was conducted in the South Gondar Zone, which is situated in the central part of the region ara and in the northwestern part of Ethiopia. T area is th ted about $668 \mathrm{~km}$ from the capital city of Ets via, Addis paba, and $103 \mathrm{~km}$ from the regional a of An ra, Ba Dar. The administrative town of a Sou Gonda one is Debre Tabor. With a popylatio of ,609,823 the Zone has 18 districts $(1,304,9$ females $1,30 \quad 12$ males $)$. There are eight govern ont spitals, 90 .olic health centers, 140 private clinics and 40. tate health facilities in the Zone. ${ }^{15}$

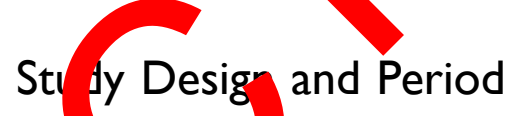

An stitutional oss-sectional study was conducted in hospit. in ty South Gondar Zone, Ethiopia, from Tanuary 2020 to 03 February 2020.

\section{Source Population}

11 mothers who delivered vaginally in South Gondar hospitals.

\section{Study Population}

All mothers who delivered vaginally during the study period in South Gondar Zone hospitals were considered as the study population.

\section{Eligibility Criteria}

The study included all mothers who gave birth and registered in the delivery registration book in hospitals in the South Gondar Zone. Mothers with postnatal complications (third degree tear, PPH, postpartum eclampsia, postpartum depression) and babies have some medical conditions that include separation from the mother; the study excluded neonates admitted to the NICU.

\section{Sample Size Determination}

The sample size was estimated using a single population proportion formula and the required sample size was determined using the following assumptions for this study; desired 
precision $(\mathrm{d})=4 \%$, confidence level $=95 \%(\mathrm{Z}$ alpha $/ 2= \pm 1.96$ value) and $81.9 \%$ of the prevalence of vaginally delivered mothers. ${ }^{16}$ Therefore, 356 was the final calculated sample size.

\section{Sampling Procedures}

In order to obtain appropriate samples, all hospitals that offer vaginal delivery service were taken. Then, using proportional allocation of size (PAS), a sample from each hospital was calculated. Finally, all mothers who delivered vaginally to get the appropriate sample size were selected using simple random sampling (see Figure 1).

\section{Operational Definitions}

Early initiation of breastfeeding: mothers who have begun breastfeeding within one hour of birth. ${ }^{16}$

Knowledge about early initiation of breastfeeding: eight knowledge-related EIBF questions were posted to mothers and each correct answer was given a value of 1 and an incorrect answer was given a value of 0 . It was dichotomized into good knowledge, mean, bad knowledge, $<$ mean, ${ }^{17}$ after measuring the sum for and respondent and mean.
Professional guidance to initiate BF: Professionals who instruct and assist the mother by explaining how to carry the infant, how to practice positioning and bonding within one hour to begin breastfeeding.

EIBF social/family support: any attendant who promotes, supports and shares the mother's experience in order to start breastfeeding within an hour.

\section{Data Collection Tools and Procedure}

For data collection, a pre-tested and structured, selfadministered questionnaire w usea. fter reviewing related work in scientific lit ture, the qu tionnaire was adopted. In order to ens the uracy of le instrument, the instrument was st prepared Ev ash, then translated to Amharic a back English by language experts. Using a stan dized a pre-t ed questionnaire, data was colle via face- fa interviews. The face-toface inurviews vere performed by six diploma holder nu nd two BS degree midwives supervised the data ollection process.

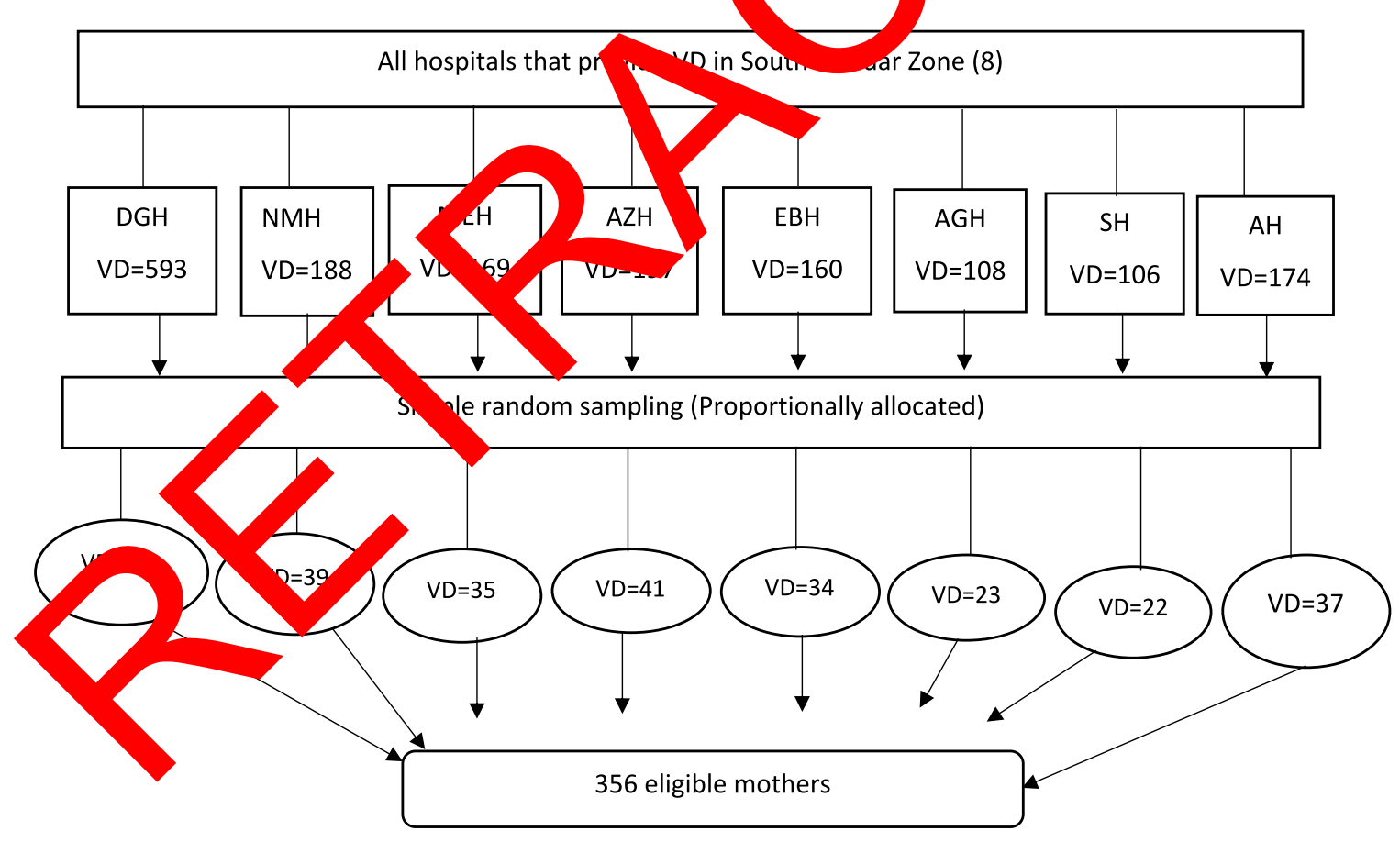

NB: DGH- Debre Tabor General Hospital, NMH- Nifas Mewucha Hospital, MEH- M/eyesus Hospital, AZH-

A/Zemen Hospital, EBH- Ebenat Hospital, AGH- Arba Gebeya Hospital, SH- Simada Hospital and AH- Andabet

Hospital.

Figure I Schematic presentation of sampling procedures in selecting VD mothers in South Gondar zone hospitals, 2020.

Abbreviations: DGH, Debre Tabor General Hospital; NMH, Nifas Mewucha Hospital; MEH, M/eyesus Hospital; AZH, A/Zemen Hospital; EBH, Ebenat Hospital; AGH, Arba Gebeya Hospital; SH, Simada Hospital; AH, Andabet Hospital. 


\section{Data Quality Assurance}

A pre-test was performed in Addis Alem hospital on 36 mothers who gave birth vaginally; the instrument was then amended accordingly. Any mistake, uncertainty or incompleteness found was immediately corrected. The data collectors were trained on the contents of the questionnaire, data collection methods and the purpose of the study for one day. The method of data collection was supervised during the data collection period by the supervisor and the investigator.

\section{Data Analysis}

Using Epi data version 3.1, the data collected was entered and cleaned, then exported to SPSS version 23 for analysis. To summarize the data, descriptive analysis was performed and the final outcome of the study was interpreted in the form of text, figures and tables. Binary logistic regression analysis was carried out to see the association between independent and dependent variables. All explanatory variables with $p<0.2$ in bivariable logistic regression were entered into a multivariable logistic regression model and a significant correlation was established based on $\mathrm{p}<0.05$ and an odds ratio with $95 \% \mathrm{CI}$ in multivariable logistic regression.

\section{Ethical Approval and Consent to Participants}

This study was carried out according the $\mathrm{H}$ sinki Declaration. Ethical clearance was Institutional Review Board (IR of Do Tabor University College of Health reference number: CHS/IRP 03-008). urther approval was also granted fro the South ndar Zone Administrative Healtb office. re purpose of the study has been told for each particin and the participants in the sty of the oht refuse or discontinue participation the search nout restriction. Written informed $\mathrm{co}$ ent was ned from each participant before data co tion and confidentiality was assured; and written inform consent was obtained from parent or guardians for those age $<18$ years.

\section{Results}

\section{Socio-Demographic Characteristics of Mothers and Their Husbands}

Of the 356 mothers, 348 mothers participated in a survey with a response rate of $97.8 \%$. The highest proportion of VD mothers in the age group was 159 (45.7\%) aged 25-29 years. The average age of the mother was $26.71(\mathrm{SD} \pm 4.8)$ years. Nearly three-fourth $259(74.5 \%)$ of VD mothers were urban residents. Almost all mothers, 342 (98.3\%) were ethnic Amhara and 272 (78.2\%) were Orthodox Christian followers. As far as mothers' educational status is mentioned, at least 184 $(52.7 \%)$ mothers have finished secondary school. As far as husbands 'educational status is concerned, 233 (67\%) mothers' husbands attended at least secondary school (see Table 1).

\section{Maternal Knowledge on ElPrand BF Experience}

Two hundred and sixty-seven (76. mothers 1 ew about the EIBF. With regard to th $\mathrm{IBF}$ in vation ource, 236 (67.8\%) mothers stated at the $y$ sour information on EIBF was health pro sio as. Almast all mothers, 347 (99.7\%) confirm that bre milk a to be given to the baby first af $b$. Two hus and fifty-six (73.5\%) mothers knew the re nmended time to start BF. As far as mater anowledge of EIBF is concerned, two hundre and sixty $(74,7 \%)$ mothers had good knowledge of the VIBF. Rega ing BF experience, 205 (58.9\%) of moth were erienced in BF (see Table 2).

\section{Cosuric and Health Service-Related}

\section{Characteristics}

for the form of pregnancy, 295 (84.8\%) of mothers indicated that their pregnancy was expected. Almost all 345 (99.1\%) mothers had a history of ANC visits during pregnancy. Ninety-one (26.1\%) mothers offered guidance from the EIBF during the ANC visit. As far as the EIBF's professional advice was concerned, two hundred ninety-nine $(85,9 \%)$ of mothers had professional guidance from the EIBF. Two hundred and nine $(60.1 \%)$ of mothers were multi gravidas. In terms of duration of labor pain, 330 (94.8\%) of mother's labor pain was less than 12 hours (see Table 3 ).

\section{Infant and Social-Related Characteristics}

According to this result, 180 (51.7\%) mothers gave birth to a female child. Three hundred and twenty (92\%) of mothers received social assistance from the EIBF.

\section{Proportion of ElBF Among Vaginal Delivered Mothers}

In South Gondar Zone hospitals, the total proportion of EIBF among vaginal delivered mothers was $88.2 \%$ with (95\% CI $(85 \%, 92 \%)$ with $\mathrm{p}<0.001$. 
Table I Socio-Demographic Characteristics of Mothers and Their Husbands in South Gondar Zone Hospitals, Northwest Ethiopia, 2020

\begin{tabular}{|c|c|c|c|c|}
\hline \multirow[t]{3}{*}{ Variables } & \multicolumn{4}{|c|}{ EIBF $(n=348)$} \\
\hline & \multicolumn{2}{|l|}{ Yes } & \multicolumn{2}{|l|}{ No } \\
\hline & Frequency & Percent & Frequency & Percent \\
\hline \multicolumn{5}{|l|}{ Maternal age } \\
\hline $15-19$ & 23 & 6.6 & 6 & 1.7 \\
\hline $20-24$ & 78 & 22.4 & 8 & 2.3 \\
\hline $25-29$ & 144 & 41.4 & 15 & 4.3 \\
\hline $30-34$ & 50 & 14.5 & 7 & 2 \\
\hline 35 and above & 12 & 3.4 & 5 & 1.4 \\
\hline \multicolumn{5}{|l|}{ Residence } \\
\hline Urban & 229 & 65.8 & & 8.6 \\
\hline Rural & 78 & 22.4 & & 3.2 \\
\hline \multicolumn{5}{|l|}{ Marital status } \\
\hline Married & 287 & 87.5 & & 10.1 \\
\hline Unmarried $^{\#}$ & 20 & 5.7 & & 1.7 \\
\hline \multicolumn{5}{|l|}{ Religion } \\
\hline Orthodox & 245 & 70.4 & 27 & 7.8 \\
\hline Muslim & 53 & & 11 & 3.2 \\
\hline Others* & 9 & 2.6 & 3 & 0.9 \\
\hline \multicolumn{5}{|l|}{ Maternal education } \\
\hline Not formal education & 61 & & 9 & 2.6 \\
\hline Primary school & 69 & 19. & 13 & 3.7 \\
\hline Secondary school and above & 177 & $=0$ & 19 & 5.5 \\
\hline \multicolumn{5}{|l|}{ Husband education } \\
\hline Not formal education & & 15.2 & 6 & 1.7 \\
\hline Primary school & & 14.4 & 6 & 1.7 \\
\hline Secondary school and above & & 58.6 & 29 & 8.3 \\
\hline \multicolumn{5}{|l|}{ Maternal occupation } \\
\hline Government employed & 37 & 10.6 & 4 & 1.1 \\
\hline Self employed & 68 & 19.5 & 8 & 2.3 \\
\hline Daily laborer & $\Rightarrow$ & 5.5 & 9 & 2.6 \\
\hline Farmer & 117 & 33.6 & 10 & 2.9 \\
\hline Others & 66 & 19 & 10 & 2.9 \\
\hline Gov & 92 & 28 & 7 & 2.1 \\
\hline Self en & 118 & 35.9 & 12 & 3.6 \\
\hline Daily labo & 21 & 6.4 & 5 & 1.5 \\
\hline Farmer & 65 & 19.8 & 9 & 2.7 \\
\hline
\end{tabular}

Notes: Other*, Protestant, catholic, Jehovah, no religion; " Single, divorced and widowed.

\section{Reasons for Late Initiation of BreastFeeding}

The main reasons for delayed (late) initiation of breastfeeding claimed by the study participants were $58.3 \%$ of pain and discomfort, $33.3 \%$ of delayed milk secretion, and $8.3 \%$ of no specific reason.

\section{Factors Associated with EIBF Among Vaginal Delivered Mothers}

In order to test EIBF practice, two models were fitted. The first model was designed to analyze EIBF-related factors among vaginal delivered mothers. Among vaginally delivered mothers, variables such as type of pregnancy and 
Table 2 Maternal Knowledge on EIBF and BF Experience in South Gondar Zone Hospitals, Northwest Ethiopia, 2020

\begin{tabular}{|c|c|c|c|c|}
\hline \multirow[t]{3}{*}{ Variables } & \multicolumn{4}{|c|}{ EIBF \& BF $(n=348)$} \\
\hline & \multicolumn{2}{|c|}{ Yes } & \multicolumn{2}{|c|}{ No } \\
\hline & \multicolumn{2}{|c|}{$\begin{array}{l}\text { Frequency } \\
\text { Percent }\end{array}$} & \multicolumn{2}{|c|}{$\begin{array}{l}\text { Frequency } \\
\text { Percent }\end{array}$} \\
\hline \multicolumn{5}{|l|}{ Did you hear about BF? } \\
\hline Yes & 197 & 56.6 & 70 & 20.1 \\
\hline No & 32 & 9.2 & 49 & 14.1 \\
\hline \multicolumn{5}{|l|}{ Source of Information } \\
\hline Health professional's & 159 & 45.7 & 77 & 22.1 \\
\hline Media & 76 & 21.8 & 36 & 10.3 \\
\hline \multicolumn{5}{|l|}{$\begin{array}{l}\text { Did you know recommended timing } \\
\text { of initiating of BF? }\end{array}$} \\
\hline Yes & 218 & 62.6 & 38 & 10.9 \\
\hline No & 63 & 18.1 & 29 & 8.3 \\
\hline \multicolumn{5}{|l|}{ Maternal knowledge on EIBF \& BF } \\
\hline Good & 233 & 66.9 & 27 & 7.7 \\
\hline Poor & 74 & 21.3 & 14 & 4.0 \\
\hline \multicolumn{5}{|l|}{ Breastfeeding experiences } \\
\hline Yes & 187 & 53.7 & 18 & 5.2 \\
\hline No & 120 & 34.5 & 23 & 6.6 \\
\hline
\end{tabular}

professional advice for EIBF were significantly associated with EIBF. In contrast to mothers with unint pregnancy, mothers with planned pregnancy y 6.00 mes (AOR $=6.00,95 \% \mathrm{CI}=2.86,12.56)$ more within one hour. Mothers who obtr ed profe onal guidance from the EIBF were 2.75 no nore likely start BF early than those motherc who did in receive professional guidance from the $\mathrm{BF}(\mathrm{AOR}=2.75,-\mathrm{CI}=1.20$, 6.34). Mothers with of exp Aence were 1.79 times $(\mathrm{AOR}=1.79,95 \% \mathrm{CI}=1.68) \mathrm{m}$ likely than their counterparts ty cart fo with on cour (see Table 4).

\section{Discussic}

The goal of this $\mathrm{s} y$ was to determine the prevalence of EIBF and associated factors among mothers with vaginal delivery in the South Gondar Zone of Northwest Ethiopia.

The study found that the prevalence of early initiation of breastfeeding among vaginal delivery within one hour was $88.2 \%$. The result was consistent with the study in Bahir Dar, Ethiopia (87\%). ${ }^{18}$ This may be due to the similarity of the nature of the study, the social demographic variables and the population of the study.
Table 3 Obstetric and Health Service-Related Characteristics of Mothers versus EIBF Among VD Mothers in South Gondar Zone Hospitals, Northwest Ethiopia, 2020

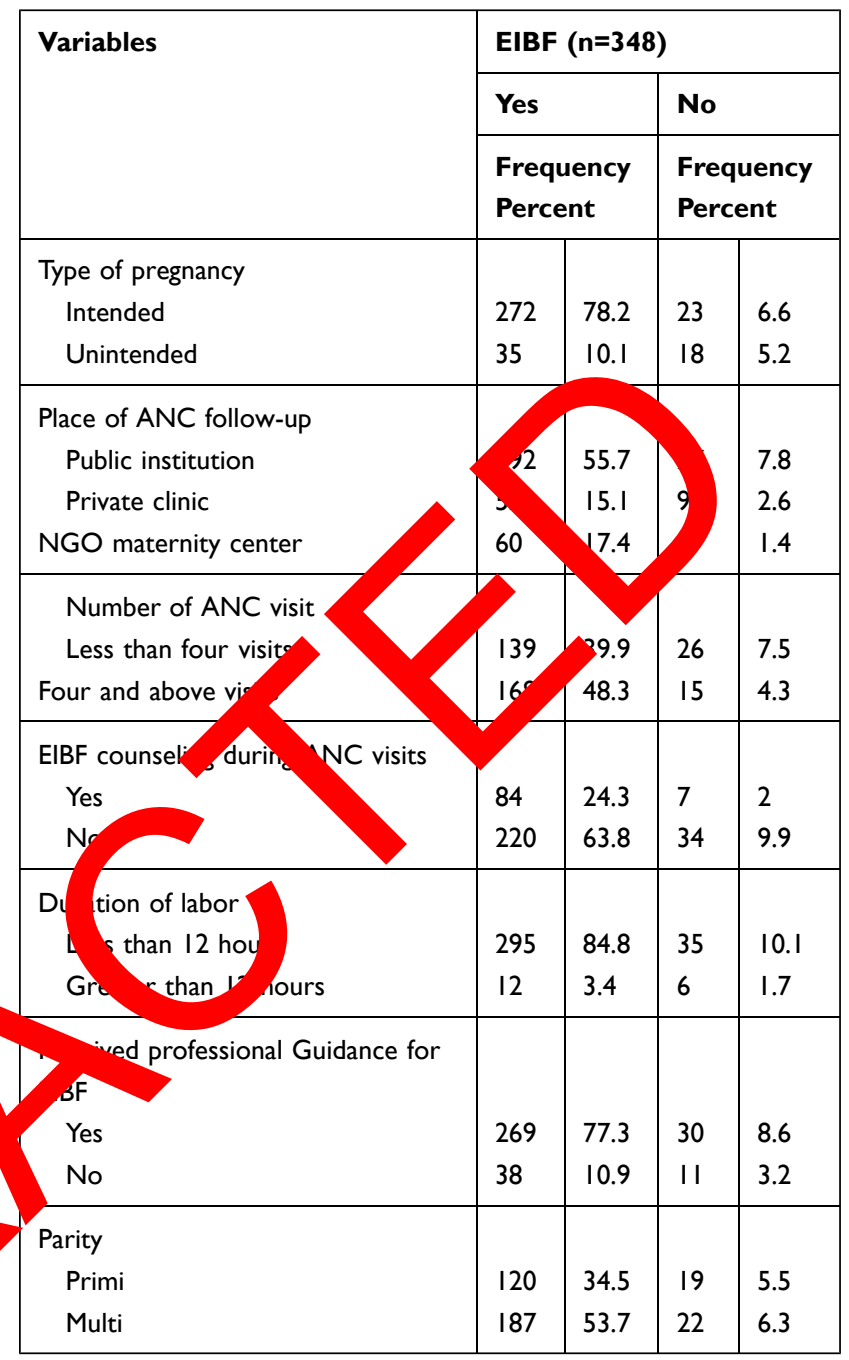

On the other hand, this result was higher than the two studies in Bangladesh, which were $57 \%$ and $67 \%$ among vaginal delivered mothers. ${ }^{19,20}$ This disparity may be due to the difference in nature of the study, because the study performed in Bangladesh was an observational study, but this study was a cross-section study.

This result was also higher compared to the study conducted in India $(65.2 \%),{ }^{21}$ Nepal $(55 \%)^{22}$ and Bangladesh $(67 \%)^{20}$ among vaginal delivered mothers who began breastfeeding within one hour. This disparity may be due to variations in the time of the research, the nature of the study, maternal socio-demographic characteristics such as access to information, educational status, cross-cultural disparities in breastfeeding practice and the characteristics of health service use. 
Table 4 Multivariable Analysis of EIBF Among VD Mothers in South Gondar Zone Hospitals, Northwest Ethiopia, 2020 (N= 348 )

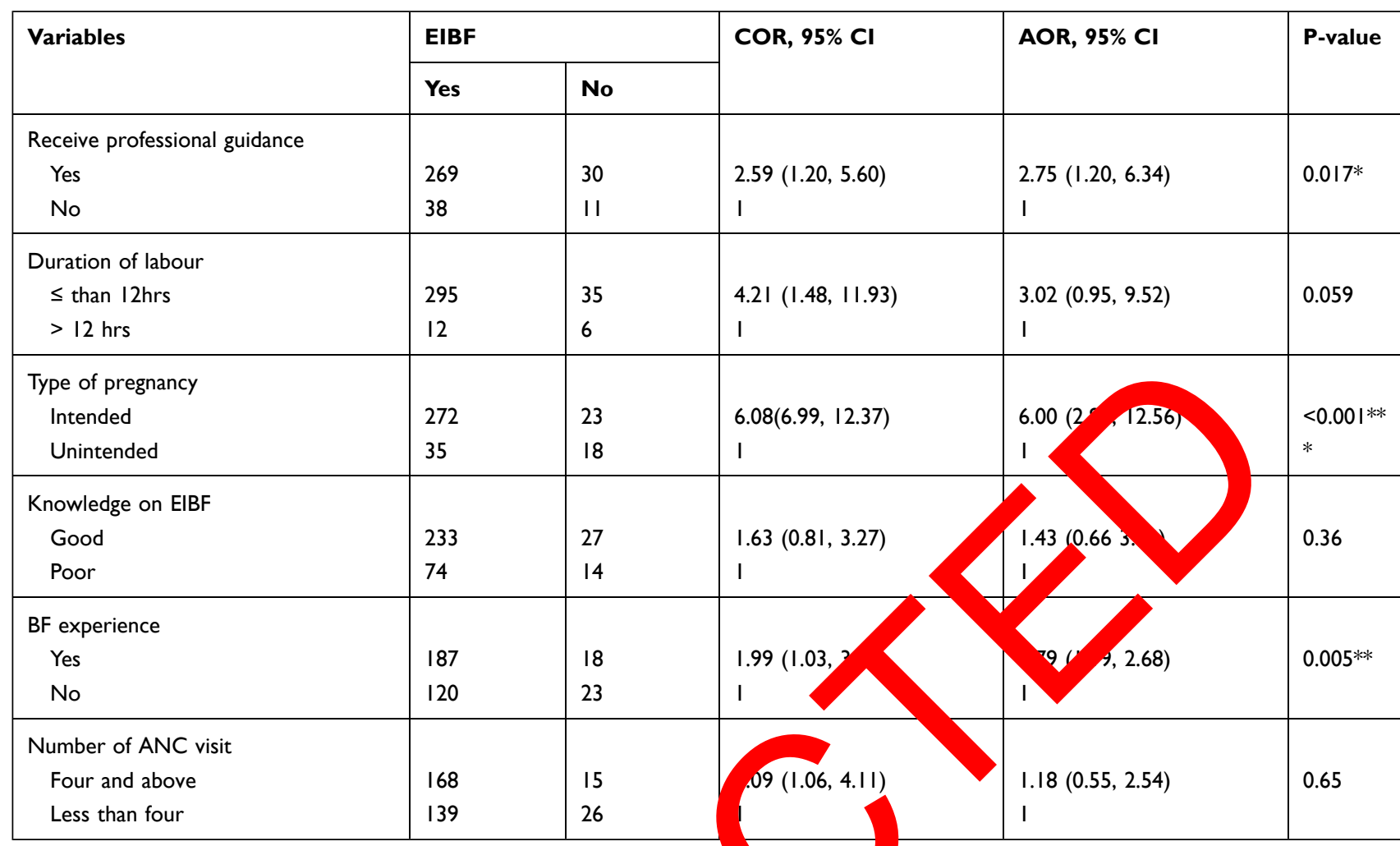

Notes: *p-value $<0.05,{ }^{*}$ p-value $<0.01$.

However, the EIBF rate in our study was $88.2 \% \mathrm{~h}$ her than the other studies performed in Ethiopia to $75.7 \%$ in 2016$),{ }^{23}$ Debre Tabor $16.8 \%$ ) Tigra $(61.9 \%)^{25}$ and Wolayita zone $(81.1 \%)$. Thi may be attributable to the stud time ga as the study develops their awareness, atti de d practice ards early initiation of breastfeeding close to th century.

The results of the altivariate analy showed that the variables were sta ically onificant to the practice of the EIBF, including po onal gy lance received, unintended pre ang and $\mathrm{p}, \mathrm{r}$ e crience of breastfeeding.

Thi result lowed tha the professional guidance received as astam correlated with early initiation of breastfec g. This finding was supported by studies conducted in Brazil $^{27}$ Indonesia, ${ }^{28}$ Bangladesh, ${ }^{20}$ Romania $^{29}$ and Uganda; ${ }^{30}$ which showed that professional assistance or advice after delivery increased the EIBF by mothers.

This may be due to the fact that the support and inspiration of health professionals encourages mothers to take a stand in EIBF service. A professional and welltrained health-care provider can encourage mothers to encourage early breastfeeding and explain the benefits of ear oreastfeeding, counseling on the risks and long-term risks of pre-lacteal feeding, and the benefits of the EIBF and the continuation of breastfeeding. ${ }^{31}$

The type of pregnancy has also been significantly associated with EIBF for mothers with vaginal delivery. According to this result, mothers with intended pregnancy were more likely to initiate BF early than mothers with unintended pregnancy, which was consistent with studies conducted in Turkey, ${ }^{32}$ Philippines $^{33}$ and Eastern zone Tigray Ethiopia. ${ }^{25}$ This may be explained by the fact that the attitude of women towards their baby will affect their probability of child care and, ultimately, their decision to initiate breastfeeding timely.

Mothers who had prior breastfeeding experience were 1.79 times more likely to start breastfeeding within one hour compared to their counterparts. This finding was supported by studies in Tabriz [35], Nigeria, ${ }^{34}$ and Egypt. ${ }^{35}$ The reason for this may be due to the exposure of mothers who have breastfeeding experience to professional counseling, their experience of how to feed the baby breast and how to hold and attach the baby could assist mothers to start early breastfeeding.

One of the strengths of this study random selection of almost 356 women from a representative list should 
minimize the likelihood of selection bias. This study has some limitations. First; data of the study are crosssectional nature of the study limits to set a causal-effect relationship between dependent and independent variables. Second; since it is based on mothers report the exact time that is the first one hour after birth might be difficult to measure. Third; selection bias might be also the limitation of the study. Forth; vaginal delivered mothers delivered in health centers in south Gondar zone were not included.

\section{Conclusions}

In the study area, the prevalence of early initiation of early breastfeeding was high. Professional advice on EIBF, type of pregnancy and prior experience of breastfeeding among vaginal delivered mothers was significantly associated with early initiation of breastfeeding. Community-based breastfeeding education and counseling is recommended for pregnant mothers and encourages all mothers to promote early breastfeeding.

\section{Abbreviations}

BF, Breastfeeding; EDHS, Ethiopian Demographic and Health Survey; EIBF, Early initiation of breastfeedir NICU, Neonatal intensive care unit.

\section{Acknowledgments}

The author would like to acknowledg Debr University for ethical clearance and ter acal su, ,rt as well as the study participants and data crors and sup visors.

\section{Funding}

This research receive o spec grant from any funding agency in the public, con cial or $y$-for-profit sectors.
4. Victora CG, Bahl R, Barros AJD, et al. Breastfeeding in the 21st century: epidemiology, mechanisms, and lifelong effect. Lancet. 2016;387(10017):475-490. doi:10.1016/S0140-6736(15)01024-7

5. Karkee R, Lee AH, Khanal V, et al. Initiation of breastfeeding and factors associated with prelacteal feeds in Central Nepal. J Human Lactation. 2014;30(3):353-357. doi:10.1177/089033441 4529845

6. Edmond KM, et al. Delayed breastfeeding initiation increases risk of neonatal mortality. Pediatrics. 2012;117(3):e380-e386. doi:10.1542/ peds.2005-1496

7. https://data.unicef.org.Child-survival/neonatal-mortality. 2017.

8. Woldemichael B. Timely initiation of breastfeeding and its associated factors among mothers in Tiyo Woreda, Arsi Zone, Ethiopia: A community-based cross sectional study. Clinics Mother Child Health. 2016;13(1) doi:10.4172/20907214.1000221

9. Baye K. Estimates of Dietary Qualit Infants and 1 ng Children (6-23 Months): evidence from Demos hic and Heal Surveys of 48 Low-And Middle-Income untries'. 'RN Elect iic J. 2018. doi: $10.2139 /$ ssrn.3279184

10. IBFAN. Report on the S-ation of I $\mathrm{I}$ t and Yo, Child Feeding in Ethiopia. April 2015

11. Senarath U, Siri dena odakanda SS, Jayawickrama H, Fernando DN ley MJ. De inan of breastfeeding practices: an analysic i Sri Lanka ographic and health survey 2006-2007. Matern ijld Nutr. 2012;8(3):315-329. doi:10.1111/ j.1740 2011.0032 \%

12. A rari M, Khanal V, Kan R, Gavidia T. Factors associated with fy initiation of breastfeeding among Nepalese mothers: further alysis of $\mathrm{Nc} 1$ Demographic and Health Survey, 2011. I. Rreastfeed J. 14;9(1):21. doi:10.1186/s13006-014-0021-6

13. Ip al. Br ceeding and maternal and infant health outcomes in developa countries. Evid Rep Technol Assess (Full Rep). 153:1-186.

Centra. Stastics Agency (CSA). Ethiopian Demographic Health Survey; 2016.

5. Survey of South Gondar Zonal Health Office Report. Health department office, 2019.

6. Butte NF, Lopez-Alarcon MG, Garza C. Nutrient Adequacy of Exclusive Breastfeeding for the Term Infant During the First Six Months of Life. World Health Organization; 2002.

17. Chekol DA, et al. Exclusive breastfeeding and mothers' employment status in Gondar town, Northwest Ethiopia: a comparative crosssectional study. Int Breastfeed J. 2017;12(1):27. doi:10.1186/s13006017-0118-9

18. Musa Seid A. Vaginal delivery and maternal knowledge on correct breastfeeding initiation time as predictors of early breastfeeding initiation: lesson from a community-based cross-sectional study. ISRN Epidemiol. 2014;2014:904609. doi:10.1155/2014/ 904609

19. Samad N, Haque M, Sultana S. Pattern of delivery and early initiation of breastfeeding: an urban slum based cross cut study. $J$ Nutr Health Food Engineering. 2017;7:00244.

20. Karim F, Billah SM, Chowdhury MAK, et al. Initiation of breastfeeding within one hour of birth and its determinants among normal vaginal deliveries at primary and secondary health facilities in Bangladesh: a case-observation study. PLoS One. 2018;13(8): e0202508. doi:10.1371/journal.pone.0202508

21. Badaya N, Jain S, Kumar N. Time of initiation of breastfeeding in various modes of delivery and to observe the effect of low birth weight and period of gestation on initiation of breastfeeding. Int J Contemporary Pediatrics. 2018;5(4):1509-1517. doi:10.18203/ 2349-3291.ijcp20182555

22. Ghimire U. The effect of maternal health service utilization in early initiation of breastfeeding among Nepalese mothers. Int Breastfeed J. 2019;14(1):33. doi:10.1186/s13006-019-0228-7 
23. Ahmed KY, Page A, Arora A, et al. Trends and determinants of early initiation of breastfeeding and exclusive breastfeeding in Ethiopia from 2000 to 2016. Int Breastfeed J. 2019;14(1):40. doi:10.1186/ s13006-019-0234-9

24. Abie BM, Goshu YA. Early initiation of breastfeeding and colostrum feeding among mothers of children aged less than 24 months in Debre Tabor, northwest Ethiopia: a cross-sectional study. BMC Res Notes. 2019;12(1):65. doi:10.1186/s13104-019-4094-6

25. Gebremeskel SG, Gebru TT, Gebrehiwot BG, et al. Early initiation of breastfeeding and associated factors among mothers of aged less than 12 months children in rural eastern zone, Tigray, Ethiopia: cross-sectional study. BMC Res Notes. 2019;12(1):671. doi:10.1186/ s13104-019-4718-x

26. Lake E, Gelaw K. Prevalence of timely initiation of breastfeeding practice among primiparous mothers at Bedessa Town, Wolaita Zone, Southern Ethiopia, 2018: A community based cross-sectionals study. J Preg Child Health. 2019;6(408):2.

27. Vieira TO, Vieira GO, Giugliani ERJ, et al. Determinants of breastfeeding initiation within the first hour of life in a Brazilian population: cross-sectional study. BMC Public Health. 2010;10(1):760. doi:10.1186/1471-2458-10-760

28. Nisa J, Salimo H, Budihastuti UR. Factor of socio demography and obstetric that influence the timeliness of early breastfeeding in tegal regency. J Maternal Child Maternal. 2017;2(2):89-99. doi:10.26911/ thejmch.2017.02.02.01
29. Cozma-Petruţ A, Badiu-Tişa I, Stanciu O, et al. Determinants of early initiation of breastfeeding among mothers of children aged less than 24 months in Northwestern Romania. Nutrients. 2019;11(12):2988. doi:10.3390/nu11122988

30. Kalisa R, Malande $\mathrm{O}$, Nankunda $\mathrm{J}$, et al. Magnitude and factors associated with delayed initiation of breastfeeding among mothers who deliver in Mulago hospital, Uganda. Afr Health Sci. 2015;15 (4):1130-1135. doi:10.4314/ahs.v15i4.11

31. Falle TY, et al. Potential role of traditional birth attendants in neonatal healthcare in rural southern Nepal. J Health Popul Nutr. 2009;27(1):53.

32. Yılmaz E, Doğa Öcal F, Vural Yılmaz Z, et al. Early initiation and exclusive breastfeeding: factors influencing the attitudes of mothers who gave birth in a baby-friendly hospital. Turkish $J$ Obstetrics Gynecol. 2017;14(1):1. doi:10.4274/tjod.90018

33. Ulep VGT, Borja MP. Association betwe rnancy intention and optimal breastfeeding practices in the Phil nes: a c sectional study. BMC Pregnancy Childbirth. 2012;12(1) doi:10.1186/1 -2393-12-69

34. Berde A, Yalçın S. Determinant fearly initiatic of breastfeeding in Nigeria: a population bo d study ing the 201 demographic and health survey data. MC Pregna Ch' firth. 2016;16:16 doi:10.1186/s12884

35. Mohamed S, Zaki E, Ty A. Barriers of Initiation and exclusive breast fer ig am ants. IOS Nursing Health Sci. 2016;5 (2):01-10

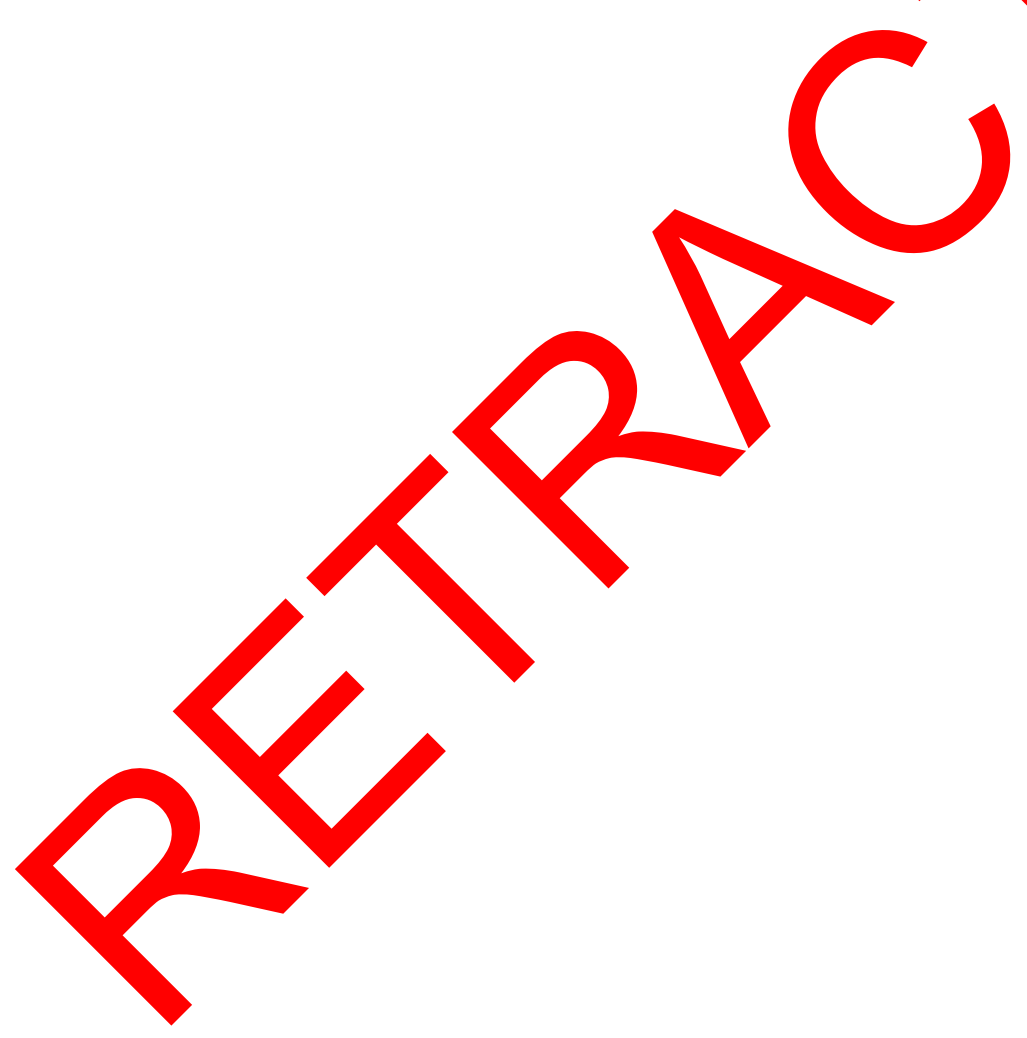

International Journal of Women's Health

Dovepress

\section{Publish your work in this journal}

The International Journal of Women's Health is an international, peerreviewed open-access journal publishing original research, reports, editorials, reviews and commentaries on all aspects of women's healthcare including gynecology, obstetrics, and breast cancer. The manuscript management system is completely online and includes a very quick and fair peer-review system, which is all easy to use. Visit http://www.dovepress.com/testimonials.php to read real quotes from published authors. 